Gunahumas

p-ISSN: 2338-1507

Jurnal Kehumas

Vol 3, No 2, 2020, 35-42

\title{
Penerapan E-Modul Untuk Meningkatkan Comunication Skills Bahasa Inggris
}

\author{
Toto Ruhimat ${ }^{1}$, Siti Ahadiah Nurjanah ${ }^{2}$ \\ ${ }^{1}$ Educational Technology Department of Universitas Pendidikan Indonesia, \\ Email: toto_ruhimat@upi.edu \\ ${ }^{2}$ Sekolah Menengah Pertama Negeri 2 Leuwi Goong, Kabupaten Garut. \\ Email: siti.ahadiah80@gmail.com
}

\begin{abstract}
Abstrak
Penelitian dilakukan dengan tujuan untuk mendeskripsikan peningkatan communication skills setelah diterapkan model ADDIE berbantuan e-modul pada mata pelajaran Bahasa inggris. Penelitian ini menggunakan metode quasy exsperiment dengan desain nonequivalent control group. Populasi dalam penelitian ini adalah semua siswa kelas VII di salah satu SMP di Kabupaten Garut. Dan sampel dalam penelitian ini adalah kelas VII B diambil dengan menggunakan teknik simple random sampling. Peningkatan comunication skills diukur dengan menggunakan 10 pertanyaan. Hasil penelitian menunjukkan bahwa siswa yang menggunakan e-modul berbasis ADDIE lebih tinggi rata-ratanya sebesar 0,4 daripada siswa yang tidak menggunakan e-modul hanya 0,1. Dari hasil tersebut maka ada rekomendasi bahwa model ADDIE berbantuan e-modul ini dapat menjadi solusi dalam peningkatan communication skills siswa.
\end{abstract}

Katakunci: Analysis Design Develop Implementation Evaluation; Bahasa Inggris; Comunication Skills; Elektronics-Modul

\begin{abstract}
The research was conducted with the aim of describing the improvement of communication skills after the application of the ADDIE model assisted by e-modules in English subjects. This study used a quasy experiment method with a nonequivalent control group design. The population in this study were all students of grade VII in one junior high school in Garut Regency. And the sample in this study is class VII B taken using simple random sampling technique. Improvement in communication skills as measured by using 10 questions. The results showed that students who used ADDIE-based e-modules were higher, with an average of 0.4 students who did not use emodules only 0.1 . From these results, there is a recommendation that the ADDIE model assisted by e-module can be a solution in improving student communication skills.
\end{abstract}

Keywords: Analysis Design Develop and Evaluation; Communication Skills; English; Electronics-Module 


\section{PENDAHULUAN}

Dalam suatu pembelajaran Bahasa Inggris, guru perlu memberikan motivasi kepada siswa agar mereka mau dan mampu menyelesaikan persoalan Bahasa Inggris, dan bila perlu membimbingnya sampai mereka dapat menyelesaikannya. Bimbingan yang dimaksud dapat diberikan secara lisan ataupun secara tertulis, namun bantuan secara tertulis dalam bahan ajar jauh lebih efektif, karena dapat dibaca secara berulang-ulang dan dipelajari oleh siswa. E-Modul merupakan salah satu alternatif pembelajaran yang tepat bagi siswa karena e-modul membantu siswa untuk menambah informasi tentang konsep yang dipelajari melalui kegiatan belajar secara sistematis. Perkembangan ilmu pengetahuan dan teknologi yang semakin canggih untuk membuat proses pembelajaran yang menyenangkan dan menarik tidaklah sulit. Menciptakan proses pembelajaran yang menarik dan menyenangkan yaitu dapat memanfaatkan ilmu teknologi, seperti yang dijadikan sebagai bahan ajar untuk menunjang proses pembelajaran berlangsung.

Bahan ajar merupakan seperangkat materi/substansi pembelajaran (teaching material) yang disusun secara sistematis, menampilkan sosok utuh dari kompetensi yang akan dikuasai siswa dalam kegiatan pembelajaran. Sebuah bahan ajar paling tidak mencakup antara lain, petunjuk belajar (petunjuk siswa/guru, kompetensi yang akan dicapai, konten atau isi materi pembelajaran, informasi pendukung, latihan-latihan, petunjuk kerja (dapat berupa Lembar Kerja), evaluasi, respon atau balikan terhadap hasil evaluasi. Keutuhan bahan ajar memungkinkan siswa untuk mempelajari suatu kompetensi atau KD secara runtut dan sistematis sehingga secara akumulatif mampu menguasai semua kompetensi secara utuh dan terpadu. Berdasarkan teknologi yang digunakan, bahan ajar dapat dikelompokkan menjadi empat kategori. Yang pertama, bahan cetak (printed) seperti handout, buku, modul, lembar kerja siswa, brosur, leaflet, wallchart, foto/gambar, model/maket. Yang kedua, bahan ajar dengar (audio) seperti kaset, radio, piringan hitam, dan compact disk audio. Yang ketiga, bahan ajar pandang dengar (audio visual) seperti video compact disk, film dan yang ke empat, bahan ajar multimedia interaktif (interactive teaching material) seperti CAI (Computer Assisted Instruction), compact disk (CD) multimedia pembelajaran interaktif, dan bahan ajar berbasis web (web based learning materials). Dari kajian riset ini maka muncul sebuah pertanyaan mendasar tentang "Bagaimanakah penerapan E-Modul dalam meningkatkan Communication Skill pada Pembelajaran Bahasa Inggris di kelas VIII SMPN Leuwigoong?”.

\section{KAJIAN LITERATUR}

Pengusaha mengeluh tentang kurangnya soft skill di antara lulusan dari lembaga pendidikan (Bernd. 2008). Ini disebabkan oleh soft skill tidak termasuk dalam kurikulum, tetapi mereka harus menjadi bagian dari pendidikan tersier sehingga siswa tidak serius (M.Riemer. 2007). Keterampilan dasar siswa telah diperoleh. Ada kemungkinan bahwa kurangnya keterampilan siswa desain kursus yang buruk, tidak pengiriman instruksional yang tidak memadai spesifik menyebabkan 


\section{Gunahumas}

Jurnal Kehumas

kurangnya kompetensi siswa perlu dieksplorasi lebih lanjut (D. Norah 2006). Oleh karena itu, guru dituntut untuk mengintegrasikan soft skill dalam belajar secara menyeluruh, efektif dan efisien. Soft skill adalah dasar mendasar dari keterampilan penting dalam kehidupan manusia dan siswa (H.Serkan. 2014), auditor internal (Smith. 2005), pemilihan manajer dan guru (M. Bambacas, and P. Margaret. (2009). Keterampilan lunak termasuk keterampilan komunikasi, kreativitas keterampilan pemecahan masalah, pemikiran kritis dan terstruktur, kemampuan kerja tim, keterampilan negosiasi, manajemen diri, imajinasi, rasa ingin tahu, tekad, semangat, atau ketekunan dapat ditambahkan. Agar sederhana dari definisi itu, dalam (Arikunto, 2013), dipisahkan menjadi tiga kategori, yaitu kualitas pribadi, keterampilan interpersonal, dan keterampilan / pengetahuan tambahan. Auditor perlu memiliki keterampilan komunikasi untuk berhasil dan maju untuk mengubah global, pasar global yang kompleks. Pada pemilihan manajer, pemimpin menggunakan keterampilan komunikasi untuk karyawan yang dapat diandalkan dalam berurusan dengan pelanggan. Pendidik untuk mempromosikan siswa tentang keterampilan komunikasi dengan meningkatkan interaksi teman sebaya, merangsang penalaran siswa, dan dalam membangun pengetahuan sosial bersama (Chung 2016). Keterampilan komunikasi dapat dibangun mengikuti kegiatan komunikatif seperti diskusi, pemecahan masalah (Oradee. 2012), model, multimedia, poster dan presentasi lisan ( $\mathrm{S}$. Ornit 2009).
p-ISSN: 2338-1507

Vol 3, No 2, 2020, 35-42

Model ADDIE adalah model yang berpusat pada siswa dan dapat memfasilitasi siswa dalam mengembangkan proses berdasarkan sistematik (Aldoobie, 2015); (Arkün and Akkoyunlu 2008); (McGriff 2000). Ketika tahapan model Pembelajaran ADDIE adalah analisis, desain, pengembangan, implementasi, evaluasi (Aldoobie 2015). Pada tahap analisis, ini adalah bagian dari menentukan tujuan pembelajaran. Tahap kedua adalah desain yang merupakan rencana pembelajaran yang efektif. Tahap ketiga adalah pengembangan yang dilakukan dengan mengembangkan pembelajaran berbasis materi pendukung. Tahap selanjutnya adalah penerapan berdasarkan pada aplikasi bahan pendukung untuk mengirim tingkat efektivitas dan efisiensi pembelajaran. Tahap terakhir adalah evaluasi yang harus diperbaiki, diperbaiki, atau dipindahkan dalam belajar tujuan pembelajaran (Aldoobie 2015); (McGriff 2000). Dalam model ADDIE ini dikembangkan dengan berbantuan bahan ajar e-modul Bahasa inggris yang dikembangkan dengan aplikasi 3D Page Flip.

Penelitian ini bermaksud untuk mengetahui dan meningkatkan communication skills pembelajaran bahasa Inggris melalui e-modul yang dibuat dan dilatihka menggunakan model ADDIE secara efektif, efisien dan proses pembelajaran yang memiliki kekuatan menarik. Latar belakang pertanyaan penelitian ini yang dilakukan Darmawan (2018) bahwa ketika pembelajaran yang berasal dari guru sekolah kejuruan di Indonesia yang sulit dan tidak pasti menerapkan pembelajaran berbasis WEB untuk siswa program teknik Komputer 
dan Jaringan. Untuk menjawab pertanyaan itu, para peneliti mengembangkan model pembelajaran berbasis web. Proses pengembangan dilakukan melalui Pendekatan Penelitian dan Pengembangan. WELS model ini, penggunaan pembelajaran di bidang komputer dan teknik jaringan dan hasilnya cukup efektif. Berdasarkan hal ini, penelitian ini bertujuan untuk (1) meningkatkan penguasaan kosakata bahasa Inggris tentang kesehatan siswa melalui pembelajaran video pembelajaran yang dibantu dengan komputer atau gadget, (2) meningkatkan efektivitas pembelajaran bahasa Inggris dengan dibantu dengan komputer atau gadget, (3) meningkatkan efisiensi belajar yang dibantu komputer atau gadget berbahasa Inggris, dan (4) membuat belajar bahasa Inggris menarik bagi siswa. Selanjutnya, menurut Dick dan Carey (2005), belajar adalah serangkaian kegiatan yang dilakukan secara terencana dan terorganisir dengan menggunakan satu atau beberapa media yang bertujuan bagi siswa untuk mencapai kompetensi tertentu seperti yang diharapkan sementara menurut Miarso, Y,H (2004) pembelajaran adalah upaya yang disengaja, ditujukan dan dikendalikan sehingga orang lain belajar atau perubahan yang relatif menetap pada orang lain. Upaya tersebut dapat dilakukan oleh seseorang atau tim yang memiliki kemampuan atau kompetensi dalam merancang dan atau mengembangkan sumber belajar yang diperlukan.

Banyak orang mengatakan bahwa belajar bahasa Inggris itu mudah tetapi berbicara bahasa Inggris itu sulit, mungkin itu benar, tetapi jika kita menyadari bahwa belajar bahasa Inggris tanpa latihan seperti malam tanpa bintang. Terkadang kita hanya belajar bahasa Inggris dengan cara yang kita tidak pernah ingin mengenali komponen dan elemen yang terlibat di dalamnya kita hanya memperhatikan berbicara itu. Ada sejumlah hal yang dapat kita tuju untuk meningkatkan keterampilan bahasa Inggris kita, seperti mendengarkan lagu-lagu barat, menonton film-film berbasis bahasa Inggris, dan banyak cara lainnya. Dalam pembelajaran ADDIE berbantuan E-Modul ini diharapkan siswa dapat meningkatkan communication skills khususnya dalam pembelajaran Bahasa inggris.

\section{METODOLOGI PENELITIAN}

Penelitian ini merupakan jenis penelitian kuantitatif, dengan bentuk quasy experiment. Desain penelitian yang digunakan adalah nonequivalent control group design. Selain itu, populasi dalam penelitian ini adalah semua siswa kelas VII di SMP Negeri 2 Leuwigoong dan sampelnya adalah kelas VII B. Teknik pengambilan sampel dalam penelitian ini adalah random sampling. Teknik pengumpulan data dalam penelitian ini menggunakan instrumen berbentuk lembar tes keterampilan proses sains mengacu kepada (Everaert et al., 2018). Lembar tes yang diberikan berupa 10 soal uraian. Teknik pengumpulan data dalam penelitian ini menggunakan instrumen berbentuk lembar tes keterampilan proses sains. Lembar tes yang diberikan berupa 10 soal uraian. Tujuan utama dari penelitian ini adalah untuk meningkatkan communication skills dalam bahasa Inggris, terutama di bidang keterampilan berbicara. Maka, para peneliti mengambil kelas VII dengan laki-laki 12 orang dan perempuan 16 orang di satu 


\section{Gunahumas}

Jurnal Kehumas

sekolah menengah pertama di Kabupaten Garut dengan mata pelajaran dalam bahasa Inggris. Lokasi penelitian dilaksanakan di SMPN 2 Leuwigoong Kabupaten Garut, Jawa Barat, Indonesia.

\section{HASIL DAN PEMBAHASAN}

Sebelum memulai tindakan, rencana pelajaran dibuat dan dibahas bersama-sama antara peneliti dan siswa. Ada beberapa langkah pada kegiatan intinya yang perlu ditingkatkan, yaitu untuk membahas langkahlangkah selama model ADDIE. Selain itu, pengamat mengingatkan peneliti untuk dapat mengatur waktu mereka dengan baik. Pada implementasi cyclus pertama, banyak waktu yang digunakan selama diskusi dengan masalah yang diajukan. Temuan menunjukkan ada peserta didik yang belum bisa bekerja sama dengan teman-teman mereka, ada anggota kelompok yang tidak melakukan pekerjaan yang diberikan dari pemimpin kelompok, ada dua peserta didik yang tidak fokus pada mata pelajaran Bahasa Inggris terbukti berbicara sendiri dan ada peserta didik sebagai pembanding anggota kelompok lainnya,temuan ini sesuai dengan pendapat dari (Abdullah et al., 2019). Peneliti adalah fasilitator untuk mencoba memberikan dan memahami pentingnya kerja sama, dalam kelompok, untuk menghormati orang lain, dan menghormati pekerjaan orang lain. Setelah peserta didik diperingatkan oleh para pendidik, para siswa bekerja sama lagi dalam kelompok dan juga mengingatkan bahwa setelah diskusi mereka harus melanjutkan presentasi siswa. Ketika presentasi berlangsung, hanya ada dua kelompok yang melakukan presentasi karena waktu terbatas.
p-ISSN: 2338-1507

Vol 3, No 2, 2020, 35-42

Kedua kelompok presentasi, langsung membaca hasil kerja kelompok mereka. Presentasi kelompok tidak dapat hadir baik dalam membuka, menjelaskan dan menjawab pertanyaan dari teman-temannya. Mereka baru saja membaca jawabannya, tetapi tidak semua anggota kelompok, jelas dengan apa yang tertulis. Selain itu, siswa yang bertanya selama presentasi dua kelompok, hanya tiga orang. Pada refleksi dengan pengamat, pengamat memberikan beberapa masukan sebagai bahan berubah pada pertemuan kedua. Pengamat lebih menekankan masalah belajar sintaks, karakter.

Oleh karena itu, guru membuat beberapa perubahan pada rencana pelajaran di awal pelajaran tentang ADDIE berbantuan e-modul. Pada pertemuan kedua telah ditingkatkan dalam berbagai aspek, diskusi dalam membuat soal tes adalah lebih baik, bahkan debat ketika menentukan tes item yang dipilih (Arabia and Nourah, 2011). Ini membuktikan bahwa setiap anggota kelompok sudah mulai merasakan proses penerimaan konsep-konsep baru yang dibangun dari membaca dan mendengarkan dari pendapat teman. Waktu aktif yang diperlukan untuk diskusi juga semakin cepat tetapi tidak meninggalkan esensi dari materi pelajaran. Pada presentasi telah dibuka dengan salam, memperkenalkan kelompok anggota mereka, dan membaca pertanyaan yang telah dibuat. Presenter dalam menjawab pertanyaan juga berbalik dan ketika tidak ada kekurangan teman lain harus bantu teman mereka. Demikian juga, peserta yang memberikan pertanyaan terdiri dari enam orang. Mereka mewakili kelompok mereka. Ada satu pertanyaan yang tidak bisa dijawab 
oleh anggota kelompok, lalu pertanyaan itu dilontarkan ke peserta lainnya. Ini juga menunjukkan munculnya kejujuran, keterbukaan, menghormati pendapat teman, mengakui pendapat teman-teman sekelasnya, dan dapat saran dan kritik dari satu sama lain(Rus, 2014).

\section{SIMPULAN DAN REKOMENDASI}

E-modul Bahasa inggris ini merupakan bahan ajar yang dapat dirancang guru dengan mempertimbangkan siswa dan metoda mengajar pilihan guru,adapun pilihan dalam metodel atau model yang diambil adalah model ADDIE. E-modul dinilai guru sebagai bahan ajar interaktif karena dapat memuat teks, gambar, video/animasi, quiz interaktif dan fitur interaktif lainnya yang dapat menarik perhatian siswa. E-modul juga dinilai efisien oleh guru karena mudah digunakan siswa untuk belajar. Guru diera abad 21 diharapkan akan berminat untuk membuat dan menggunakan e-modul dalam pembelajaran. Secara praktis temuan ini juga terlihat pada antusiasme guru dalam mengikuti pelatihan dan menyelesaikan emodul yang sudah dibuat sebelumnya.

Secara teoritis dari hasil penelitian ini menujukkan bahwa pengajaran dan pembelajaran Bahasa inggris menggunakan model ADDIE berbantuan e-modul dan persentasi dapat meningkatkan communication skills, kepercayaan diri, keberanian dan tanggung jawab pada diri siswa (Rehman et al., 2011). Kegiatan belajar adalah fokus siswa (siswa terpusat) sehingga mereka dapat menggunakan pengetahuan mereka untuk menyelesaikan masalahnya. Keterampilan komunikasi diperlukan abad kedua puluh satu. Perbedaan kemampuan setelah dilakukan uji statistik menunjukkan bahwaKelompok siswa yang menggunakan e-modul berbasis ADDIE lebih tinggi rataratanya sebesar 0,4 daripada siswa yang tidak menggunakan e-modul hanya 0,1 . Dari hasil tersebut maka ada rekomendasi bahwa model ADDIE berbantuan e-modul ini dapat menjadi solusi dalam peningkatan communication skills siswa

\section{REFERENSI}

Abdullah, A. Y. M. et al. (2019) 'Modeling soil salinity using direct and indirect measurement techniques: A comparative analysis', Environmental Development. Elsevier Ltd, 29(September 2017), pp. 67-80. doi: 10.1016/j.envdev.2018.12.007.

Aldoobie, N. 2015. “ADDIE Model. American International Journal of Contemporary Research.” Ekp 13 (3): 1576-80.

Arabia, S. and Nourah, P. (2011) 'Impact of alterations in teaching methodologies on learning capabilities', (November 2016).

Arikunto, Suharsimi. (2013). Dasar-Dasar Evaluasi Pendidikan. DKI JAKARTA: Bumi Aksara.

Arkün, Selay, and Buket Akkoyunlu. 2008. "A Study on the Development Process of a Multimedia Learning Environment According to the ADDIE Model and Students' Opinions of the Multimedia Learning Environment." Digital Education Review, no. 17: 1-19.

Bernd., S. (2008). "The Importance of Soft 
Gunahumas

Jurnal Kehumas

Skills: Education beyond Academic Knowledge." Journal of Language and Communication, 2008.

Chung, et al. 2016. "Enhancing Students' Communication Skills in the Science Classroom through Socieoscientific Issues." International Journal of Science and Mathematics Education, 2016.

Darmawan. (2018). Development of WebBased Electronic Learning System (WELS) in Improving the Effectiveness of the Study at Vocational High School "Dharma Nusantara". Journal of Computer Science. January 2018. Journal of Computer Science 14(4):562-573. DOI: $10.3844 /$ jessp.2018.562.573

Dick, W and L. C arey, J. O. Carey . (2005). The systematic Design of Instruction. New York : Logman.

D. Norah, et al. 2006. "Oral Communication Skills in Higher Education: Using a Performance- Based Evaluation Rubric to Assess Communication Skills. Innovative Higher Education." Irtualm-VBiblioteca Ep 31: 115-28. https://doi.org/10.1590/s180998232013000400007.

Everaert, G. et al. (2018) 'Risk assessment of microplastics in the ocean: Modelling approach and first conclusions', Environmental Pollution. Elsevier Ltd, 242, pp. 1930-1938. doi: 10.1016/j.envpol.2018.07.069.

H.Serkan. (2014). "Survey on the Communication Skills That the College Students of School of Physical Education and Sports Perceived from the Teaching Staff." International Journal of Science Culture and Sport 2: 2014.
p-ISSN: 2338-1507

Vol 3, No 2, 2020, 35-42

https://doi.org/10.1038/132817a0.

M. Bambacas, and P. Margaret. (2009). "Assessment of Communication Skills in Manager Selection: Some Evidence from Australia." Atmospheric Chemistry and Physics 7 (1): $1-13$. https://doi.org/10.1029/2008GB0032 37.

M.Riemer. (2007). Communication Skills for the 21st Centuryengineer.

McGriff, S. J. (2000). "Instructional System Design (ISD): Using the ADDIE Model." 10 (2000): 147-73.

Miarso, Y.H (2004). Menyemai Benih Teknologi Pendidikan.Jakarta: Prenoda Media.

Oradee., T. (2012). Developing Speaking Skills Using Three Communicative Activities (Discussion, ProblemSolving, and Role-Playing). International Journal of Social Science and Humanity, . Vol. 66.

Rehman, R. et al. (2011) 'Original Article Impact of alterations in teaching methodologies on learning capabilities', 61(10).

Rus, D. (2014) 'Technical communication as strategic communication characteristics of the English technical discourse', Procedia Technology. Elsevier B.V., 12, pp. 654-658. doi: 10.1016/j.protcy.2013.12.545.

S. Ornit, et. al. (2009). "Teaching Scientific Communication Skills in Science Studies: Does It Make a Difference?." International Journal of Science and Mathematics Education, 2009. 
Smith., G. (2005). "Communication Skills Are Critical for Internal Auditors." Managerial Auditing Journal, 2005. 